\title{
Validation of terrestrial water storage variations as simulated by different global numerical models with GRACE satellite observations
}

\author{
Liangjing Zhang ${ }^{1}$, Henryk Dobslaw ${ }^{1}$, Tobias Stacke ${ }^{2}$, Andreas Güntner ${ }^{1}$, Robert Dill ${ }^{1}$, and Maik Thomas ${ }^{1,3}$ \\ ${ }^{1}$ Helmholtz Centre Potsdam, GFZ German Research Centre for Geosciences, 14473 Potsdam, Germany \\ ${ }^{2}$ Max Planck Institute for Meteorology, Hamburg, Germany \\ ${ }^{3}$ Institute of Meteorology, Free University of Berlin, Berlin, Germany \\ Correspondence to: Liangjing Zhang (jzhang@gfz-potsdam.de)
}

Received: 29 June 2016 - Discussion started: 22 July 2016

Revised: 5 December 2016 - Accepted: 18 January 2017 - Published: 10 February 2017

\begin{abstract}
Estimates of terrestrial water storage (TWS) variations from the Gravity Recovery and Climate Experiment (GRACE) satellite mission are used to assess the accuracy of four global numerical model realizations that simulate the continental branch of the global water cycle. Based on four different validation metrics, we demonstrate that for the 31 largest discharge basins worldwide all model runs agree with the observations to a very limited degree only, together with large spreads among the models themselves. Since we apply a common atmospheric forcing data set to all hydrological models considered, we conclude that those discrepancies are not entirely related to uncertainties in meteorologic input, but instead to the model structure and parametrization, and in particular to the representation of individual storage components with different spatial characteristics in each of the models. TWS as monitored by the GRACE mission is therefore a valuable validation data set for global numerical simulations of the terrestrial water storage since it is sensitive to very different model physics in individual basins, which offers helpful insight to modellers for the future improvement of large-scale numerical models of the global terrestrial water cycle.
\end{abstract}

\section{Introduction}

Growing observational evidence underlines the important role of the terrestrial water cycle in shaping the Earth's climate. For instance, soil moisture variability alters the atmospheric circulation through its impact on evaporation, which affects regional and global climate (Koster et al., 2004; Meehl et al., 2009; Seneviratne and Stöckli, 2007). Snow cover raises surface albedo and isolates the land surface from the atmosphere. Groundwater also shows a significant lowfrequency variability that could have regional impacts on inter-annual climate variability (Bierkens and van den Hurk, 2007). Monitoring data on water availability from both in situ and remote sensing instruments are also essential for economic and societal development. It can be used to characterize extreme hydro-meteorological conditions such as flood (Chen et al., 2010) and drought (Leblanc et al., 2009). Hydrological models are important tools to forecast water resources from both short- and long-term perspectives. There is now an increasing number of models that simulate the terrestrial water cycle at large spatial scales, which generally fall into two categories: land surface models (LSMs) and global hydrology models (GHMs). LSMs focus on solving the surfaceenergy balance and can be coupled to atmospheric models, while GHMs rather focus on lateral water transfer and solving the water balance equation. Due to the different physical representation of land-surface processes, uncertainties in model structure, parameter values, and atmospheric forcing data, the performance of these models varies. There have been several model intercomparison projects, such as the 
Global Soil Wetness Project (GSWP; Dirmeyer et al., 2006; Dirmeyer, 2011), the Water Model Intercomparison Project (WaterMIP; Haddeland et al., 2011), and the Inter-Sectoral Impact Model Intercomparison Project (ISI-MPI; Schewe et al., 2014), which compare the results from a multitude of models to highlight shortcomings and inconsistencies. These projects have primarily focused on evapotranspiration or soil moisture content. Gudmundsson et al. (2012) have also evaluated nine large-scale hydrological models based on runoff observations.

The terrestrial water storage (TWS), which is understood here to contain all water components stored above and underneath the land surface, including soil moisture, the water content of snowpack, land ice, surface water, and groundwater in shallow and deep aquifers, forms an important component of the terrestrial water cycle. It is difficult to directly measure TWS on the ground due to insufficient in situ observations of the very diverse hydrological stores and fluxes. The terrestrial water budget method estimates TWS by solving the terrestrial water balance equation through the data of precipitation, runoff and evapotranspiration from observations and atmospheric reanalysis (Zeng et al., 2008; Tang et al., 2010; Rodell et al., 2011), while TWS variations can also be derived from combined atmospheric and terrestrial water-balance computations, utilizing water vapour content and moisture flux convergence from atmospheric reanalysis data and river discharge measurements (Seneviratne et al., 2004; Hirschi et al., 2006). However, these methods are highly dependent on the accuracy of the reanalysis data, which often contain systematic errors, in particular at interannual timescales and longer. The Gravity Recovery and Climate Experiment (GRACE) launched in 2002 provides a unique data source to estimate spatio-temporal variations of the Earth's water storage at regional up to global scales (Tapley et al., 2004; Wahr et al., 2004). Averaged over an arbitrary area with a spatial extent of $100000 \mathrm{~km}^{2}$ and greater, TWS derived from GRACE is believed to reach an accuracy of better than $1 \mathrm{~cm}$ equivalent water thickness (Dahle et al., 2014). Although there is a mismatch between the spatial resolution of GRACE data and that of hydrological models, the effective spatial resolution can be extrapolated to finer spatial scales through proper post-processing (Landerer and Swenson, 2012). There are now more than 13 years of GRACE data available and this length of the time series together with a recently completed reprocessing of the whole GRACE record (Dahle et al., 2012) motivates us to revisit the question of what can be learned from GRACE on the performance of global hydrological models in representing continental water storage variations.

Through the comparison of basin-averaged TWS from models with GRACE-based estimates, we intend to identify the advantages and deficiencies of a certain model and analyse the reasons for different model behaviours. Globally gridded TWS variations and uncertainties from GRACE estimated by the same post-processing procedure as described by Zhang et al. (2016) are applied. We quantitatively analyse the correspondence between TWS estimates from four available hydrological models and GRACE in 31 of the world's largest river basins. To separate the effects of atmospheric input data, all the models apply the same meteorological forcing data set. Actual evapotranspiration and runoff rates calculated with the different models are also analysed. Considering the diversity of the performance of the models in these 31 basins, we focus on time series of TWS variations in two regions which are characterized by different climate regimes, i.e. the snow-dominated catchments and the dry catchments, by looking into the TWS variation time series from models and GRACE. In addition, snow, surface water and subsurface water including root zone and/or deep layer storage from the models are also compared in order to analyse the contribution of different storage components to the total water storage. By investigating the relative performance of these different models, we intend to contribute to the future model development of both LSMs and GHMs.

\section{Data set}

\subsection{Hydrological model simulations}

For this study, we selected four different models to represent a broad range from conceptual hydrological to complex land surface models (Table 1). In order to ensure that this spread between the simulations is indeed related to the different representation of physics in the model, all the models are forced with the WFDEI data set based on ERA-Interim reanalysis data (Dee et al., 2011) that has been developed during the WATCH project (Weedon et al., 2011). This WFDEI meteorological forcing data set is a quasi-observation which combines the daily variability of the ERA-Interim re-analysis with monthly in situ observations such as temperature and precipitation (Weedon et al., 2014). There are two precipitation products available from WFDEI: (1) corrected by using the Climate Research Unit at the University of East Anglia (CRU) observations; and (2) corrected with the Global Precipitation Climatology Centre (GPCC) data set. Since the WFDEI data sets incorporating the CRU-based precipitation products cover a longer time span, they are used in our study and referred to subsequently as WFDEI-CRU.

The WaterGAP Global Hydrological Model (WGHM) is part of the Water-Global Assessment and Prognosis model (WaterGAP; Döll et al., 2003). WGHM is a conceptual water balance model with grossly simplified process representations. It is calibrated by tuning a runoff generation parameter against observed river discharge in a station-based calibration approach (Hunger and Döll, 2008). The model simulates the continental water cycle including the water storage components soil moisture within the effective root zone of vegetated areas, groundwater, canopy water, snow and surface water in rivers, lakes, reservoirs and wetlands. The latest ver- 
Table 1. Overview of the main characteristics of the four numerical models particularly considered in this study.

\begin{tabular}{|c|c|c|c|c|c|c|}
\hline Model name & Model type & $\begin{array}{l}\text { Meteorological forcing } \\
\text { variables }\end{array}$ & $\begin{array}{l}\text { Storage components } \\
\text { included }\end{array}$ & $\begin{array}{l}\text { Soil moisture } \\
\text { depth }\end{array}$ & Snow & $\begin{array}{l}\text { Potential evap- } \\
\text { otranspiration }\end{array}$ \\
\hline LSDM & LSM & $\begin{array}{l}\text { Precipitation, } \\
\text { temperature }\end{array}$ & $\begin{array}{l}\text { subsurface water (root } \\
\text { zone), snow, surface } \\
\text { water }\end{array}$ & $\begin{array}{l}\text { bucket scheme } \\
\text { without a depth }\end{array}$ & degree day & Thornthwaite \\
\hline WGHM & GHM & $\begin{array}{l}\text { Precipitation, tempera- } \\
\text { ture, shortwave incom- } \\
\text { ing radiation }\end{array}$ & $\begin{array}{l}\text { subsurface water (root } \\
\text { zone+groundwater), } \\
\text { snow, surface water }\end{array}$ & $\begin{array}{l}\text { varies with } \\
\text { rooting depth } \\
\text { of land cover }\end{array}$ & degree day & $\begin{array}{l}\text { Priestley- } \\
\text { Taylor }\end{array}$ \\
\hline JSBACH & LSM & $\begin{array}{l}\text { Precipitation, tempera- } \\
\text { ture, wind, shortwave } \\
\text { and longwave radiation, } \\
\text { surface air }\end{array}$ & $\begin{array}{l}\text { subsurface water (root } \\
\text { zone+deep layer), snow }\end{array}$ & $\begin{array}{l}\text { down bedrock } \\
\text { but at most } \\
10 \mathrm{~m}\end{array}$ & $\begin{array}{l}\text { energy } \\
\text { balance }\end{array}$ & $\begin{array}{l}\text { physical } \\
\text { parametrization }\end{array}$ \\
\hline MPI-HM & GHM & $\begin{array}{l}\text { Precipitation, tempera- } \\
\text { ture, wind, radiation, } \\
\text { humidity }\end{array}$ & $\begin{array}{l}\text { subsurface water (root } \\
\text { zone), snow, surface } \\
\text { water }\end{array}$ & $\begin{array}{l}\text { bucket scheme } \\
\text { without a depth }\end{array}$ & degree day & $\begin{array}{l}\text { Penman- } \\
\text { Montheith }\end{array}$ \\
\hline
\end{tabular}

sion of WGHM as calibrated for WFDEI-GPCC forcing (version 2.2 STANDARD; Müller Schmied et al., 2014) is used in this study. However, we run the model with WFDEI-CRU forcing without re-calibration.

The Land Surface Discharge Model (LSDM; Dill, 2008) is based on the Simplified Land Surface Scheme (SL-Scheme) and the Hydrological Discharge Model (HD-Model; Hagemann and Gates, 2003, 2001) from the Max Planck Institute for Meteorology. The global water storage variations contain surface water in rivers, lakes and wetlands, groundwater and soil moisture, as well as water stored in snow and ice. The code has been tailored to enable the simulation of continental water mass redistribution for geodetic applications that include the derivation of effective angular momentum functions of the continental hydrosphere to interpret and predict changes in the Earth's rotation (Dobslaw et al., 2010; Dill and Dobslaw, 2010), and of vertical crustal deformations as observed from GPS permanent stations (Dill and Dobslaw, 2013).

JSBACH (Raddatz et al., 2007; Brovkin et al., 2009) is a land surface model and forms together with ECHAM6 (Stevens et al., 2013) and MPIOM (Jungclaus et al., 2013) the current Max Planck Institute for Meteorology's Earth System Model (MPI-ESM). As part of the MPI-ESM, JS$\mathrm{BACH}$ includes interactive vegetation and a five-layer soil hydrology scheme to provide the lower atmospheric boundary conditions over land, particularly the fluxes of energy, water and momentum. For this study, however, JSBACH was used in an offline mode without interactive coupling to the other MPI-ESM components, but driven by prescribed WFDEI-CRU atmospheric forcing. Snow in JSBACH is treated as external layers above the soil column, with a maximum of five snow layers. Soil moisture in deep layers below the root zone is simulated and buffers extreme soil moisture conditions in the layers above.

Finally, the Max Planck Institute of Meteorology's Hydrology Model (MPI-HM; Stacke and Hagemann, 2012) is a global hydrological model. Its water flux computations are of similar complexity to land surface models, but it does not account for any energy fluxes. In addition to precipitation and temperature, it requires potential evapotranspiration as input which also was derived from the WFDEI using the PenmanMontheith equation, similarly to the Weedon et al. (2011) study. TWS from MPI-HM is simulated as the sum of soil moisture in the root zone, snow and surface water.

Some of the main characteristics of the four numerical models are presented in Table 1, which provide more information on how models are different from each other. For instance, although soil moisture and snow water are included in all the models, surface water and groundwater are simulated differently. JSBACH is the only model which does not include surface water. Groundwater is simulated by WGHM, where the anthropogenic impact such as groundwater abstraction is also considered. JSBACH does not simulate groundwater directly but includes the subsurface water in the deep layer, whereas groundwater is not considered by the other two models. We use the term subsurface water for both soil moisture and groundwater. But the impact from consideration of groundwater to TWS variations will be investigated in the following discussion.

LSDM, WGHM and MPI-HM are provided on a $0.5^{\circ}$ by $0.5^{\circ}$ grid, while JSBACH has a coarse resolution, with $1.875^{\circ}$ spacing in longitude and irregular spacing in latitude. The mean values and the linear trends estimated over the period January 2003 to December 2012 - i.e. the common period of GRACE observations and model experiments - are first removed for each grid cell. Then the TWS variations are 
averaged over the selected basins to obtain the basin-scale TWS. Since ice dynamics and glacier mass balance are not included in the numerical models applied in this study, water mass variations in Antarctic and Greenland are not considered throughout the reminder of this paper.

\subsection{TWS estimates from GRACE}

The GRACE US-German twin satellite mission provides estimates of month-to-month changes in the gravitational field of the Earth mainly based on precise K-band microwave measurements of the distance between two low-flying satellites (Wahr, 2009) since April 2002. After correcting for short-term variability due to tides in the atmosphere (Biancale and Bode, 2006), solid Earth (Petit and Luzum, 2010) and oceans (Savcenko and Bosch, 2012), as well as due to non-tidal variability in the atmosphere and oceans (Dobslaw et al., 2013) from the observations, the resulting gravity changes mainly represent mass transport phenomena in the Earth system, which are - apart from long-term trends - almost exclusively related to the global water cycle.

We use the monthly GRACE release 05a Level-2 products from GFZ Potsdam (Dahle et al., 2012), which can be downloaded from the website of the International Centre for Global Earth Models (http://icgem.gfz-potsdam.de/ ICGEM). The GRACE products are expressed in terms of fully normalized spherical harmonic ( $\mathrm{SH}$ ) coefficients up to degree and order 90 , approximately corresponding to a global resolution of $2^{\circ}$ in latitude and longitude. We apply the same post-processing steps to the GRACE data as described by Zhang et al. (2016). The degree-1 coefficients are added following the method of Bergmann-Wolf et al. (2014). The non-isotropic filter DDK2 corresponding to an isotropic Gaussian filter with $680 \mathrm{~km}$ full width half maximum (Kusche, 2007; Kusche et al., 2009) is applied to remove correlated errors at particular higher degrees of the spherical harmonic expansion. In order to account for signal attenuation and leakage caused by smoothing and filtering, local re-scaling factors are introduced for each grid cell. We use median re-scaling factors obtained from a small ensemble of global hydrological models. The gridded TWS anomalies are then estimated which can be averaged over arbitrary basins. As for the model data, the linear trend is removed over the period January 2003 to December 2012. Error estimates as a quadrature of measurement error, leakage error and re-scaling error are also provided to assess the signal-to-noise ratio (SNR) of GRACE for particular basins (full details are given in Zhang et al., 2016). In the case of a small signal-to-noise ratio, discrepancies between TWS from GRACE and models might also be attributed to comparatively large GRACE TWS errors.

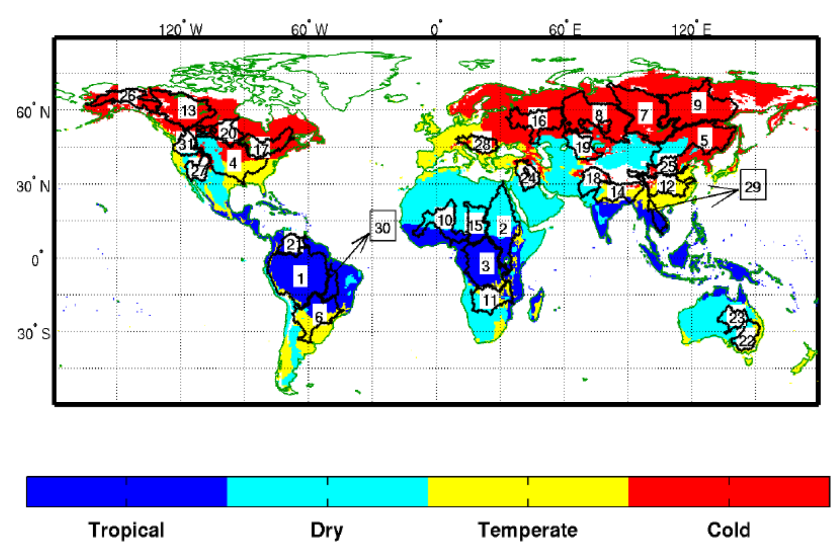

Figure 1. Locations of 31 globally distributed basins from the simulated topological networks (STN-30p) with underlying KöppenGeiger climate zones. Basin IDs and names are indicated in Table 2.

\section{Evaluation of TWS from model realizations with GRACE}

We compare the basin-averaged TWS from GRACE with the results of four different numerical model realizations introduced above. In total, 31 globally distributed basins where the GRACE SNR is larger than 2 (see Fig. 1 and Table 2) are selected for further study. We first focus on the global statistical performance of the models compared to GRACE. For these basins, evaluation metrics as suggested by Gudmundsson et al. (2012) that focus both on seasonal signals and year-to-year variability are applied.

\subsection{Evaluation metrics}

First, relative annual amplitude differences are calculated according to

$\Delta \mu=\left(\mu_{\mathrm{M}}-\mu_{\mathrm{O}}\right) / \mu_{\mathrm{O}}$,

where $\mu_{\mathrm{O}}$ is the annual amplitude of the time series of TWS variations from GRACE, and $\mu_{\mathrm{M}}$ the annual TWS amplitudes from the different model realizations (Fig. 2). Second, the timing of the annual cycle is assessed using phase differences of the annual harmonic for models and observations according to

$\Delta \phi=\phi_{\mathrm{M}}-\phi_{\mathrm{O}}$.

If the value of $\Delta \phi$ is negative, it implies that the seasonal maximum is earlier in the year in the model than in GRACE (Fig. 3). Annual amplitude and phase are calculated by least square regression as follows:

$$
\begin{aligned}
\mathrm{MIN} & \stackrel{!}{=}\left(\Delta \operatorname{TWS}(t)-(A \sin (2 \pi t / T+\phi))^{T}(\Delta \operatorname{TWS}(t)\right. \\
& -(A \sin (2 \pi t / T+\phi)),
\end{aligned}
$$

where $\Delta$ TWS is the TWS anomaly time series and $T$ is the period of 1 year. Third, the explained variances for all the 
(a) LSDM

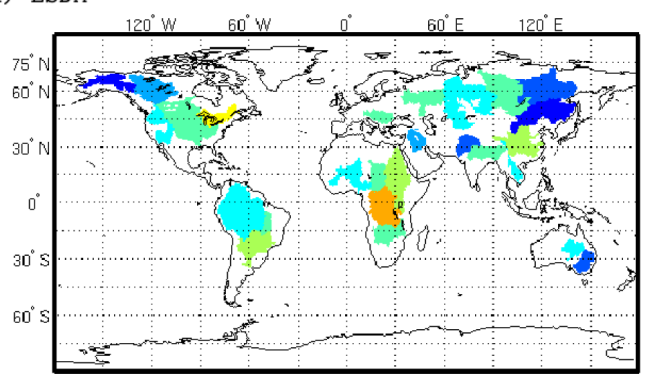

(c) JSBACH

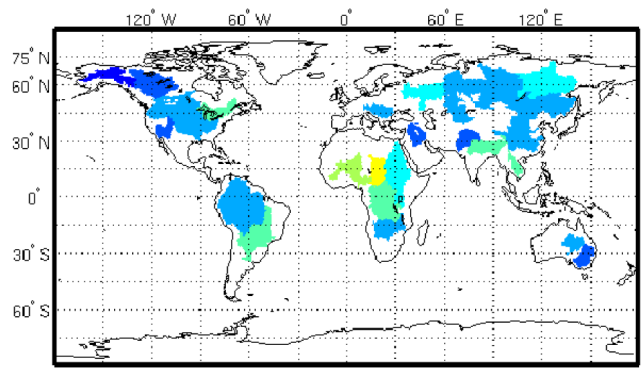

(b) WGHM

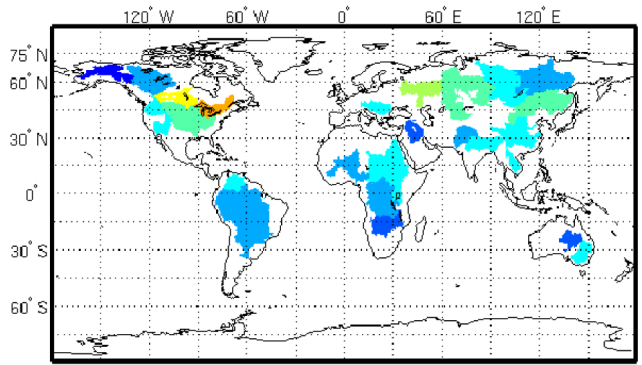

(d) MPI-HM

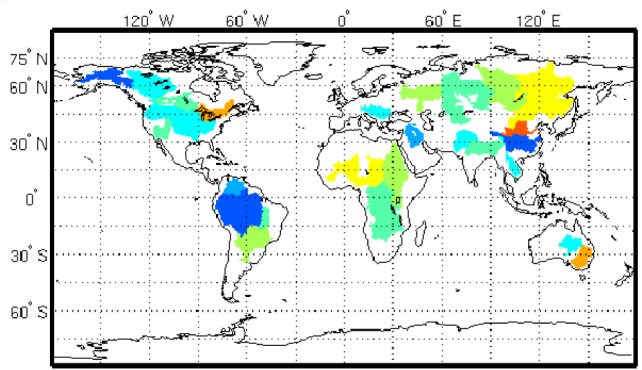

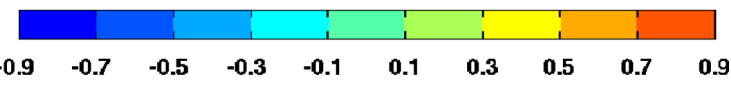

Figure 2. Relative amplitude differences of four hydrological model realizations with GRACE-based TWS observations.

(a) LSDM

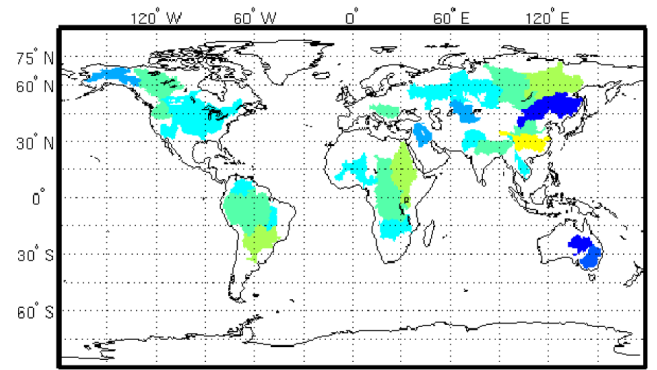

(c) JSBACH

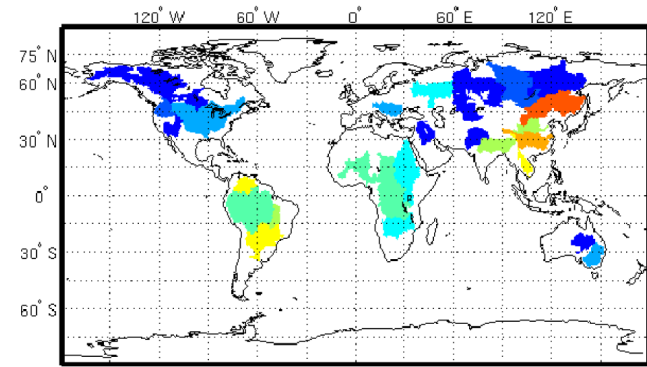

(b) WGHM

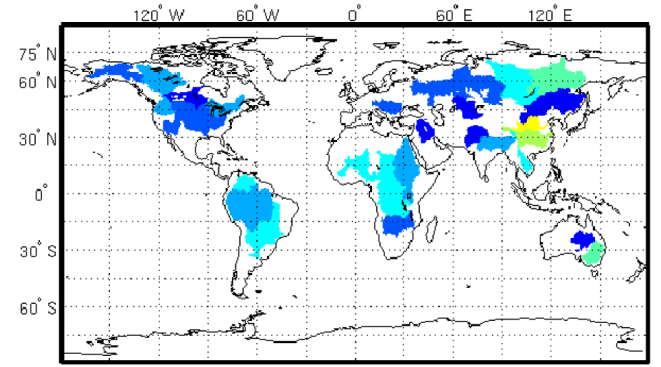

(d) MPI-HM

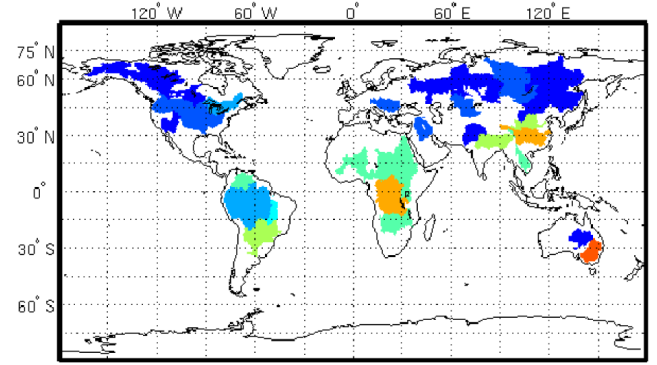

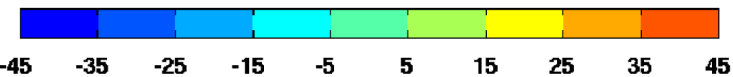

Figure 3. Phase differences for the annual signal of four hydrological model realizations with GRACE-based TWS observations. 


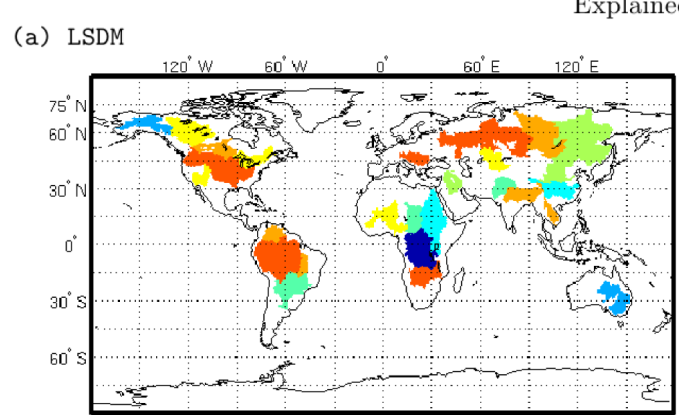

(c) JSBACH

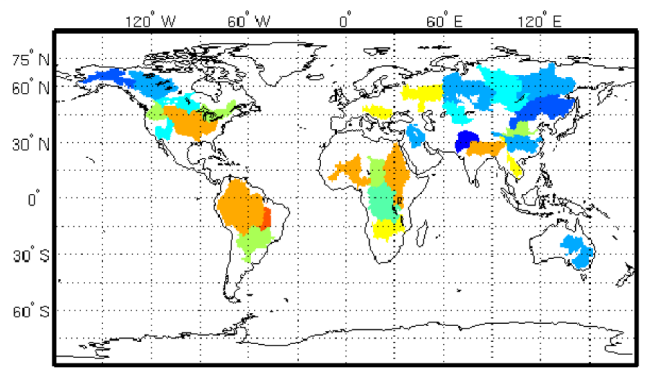

(b) WGHM

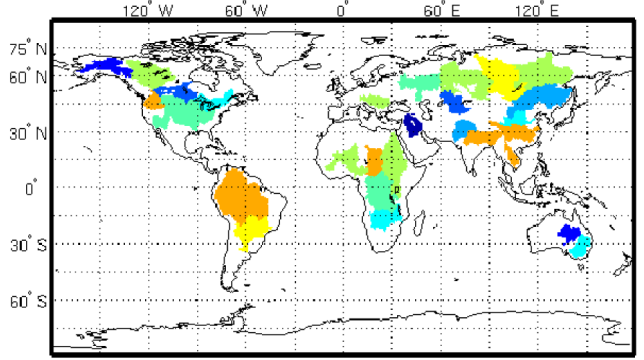

(d) MPI-HM

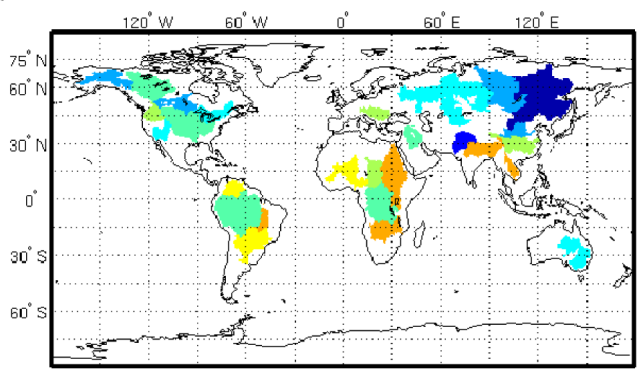

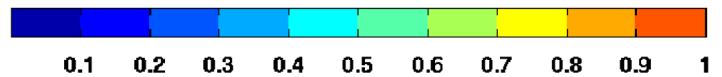

Figure 4. Variance of GRACE-based TWS observations that is explained by TWS as simulated in four hydrological model realizations.

(a) LSDM

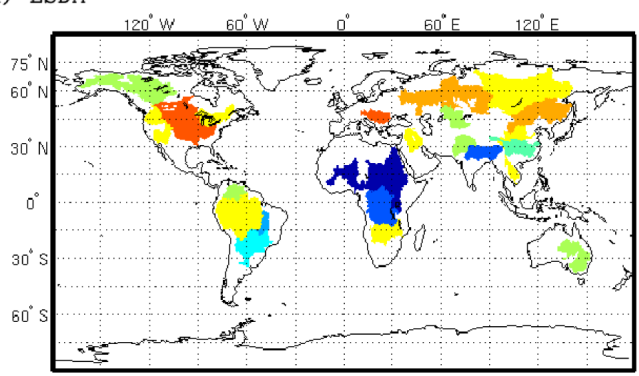

(c) JSBACH

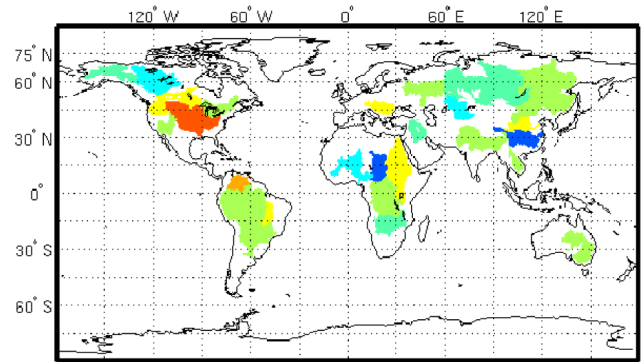

(b) WGHM

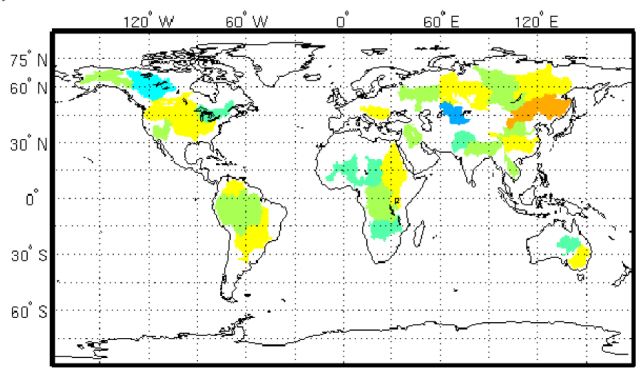

(d) MPI-HM

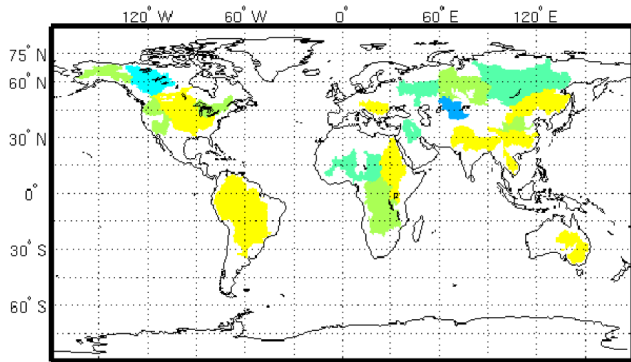

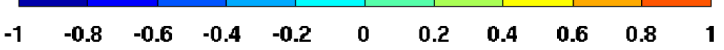

Figure 5. Variance of GRACE-based TWS observations that is explained by TWS as simulated in four hydrological model realizations. For both observations and model results, the annual harmonic signal has been removed. 
model realizations are calculated:

$R^{2}=\left(\operatorname{var}\left(\mathrm{TWS}_{\mathrm{O}}\right)-\operatorname{var}\left(\mathrm{TWS}_{\mathrm{O}}-\mathrm{TWS}_{\mathrm{M}}\right)\right) / \operatorname{var}\left(\mathrm{TWS}_{\mathrm{O}}\right)$,

where var denotes the variance operator. Fourth, we repeat the calculation of the explained variances for TWS time series from GRACE and the models with the mean seasonal variability removed.

\subsection{Global evaluation}

As shown in Fig. 2, the values of $\Delta \mu$ for WGHM and JS$\mathrm{BACH}$ are mostly negative. For JSBACH, these negative values mainly occur at mid to high latitudes of the Northern Hemisphere. WGHM underestimates the annual amplitude, especially at the low latitudes. Contrarily, MPI-HM has more basins with positive $\Delta \mu$. For LSDM, most $\Delta \mu$ values lie between -0.3 and 0.3 , indicating on average better agreement of annual amplitude with GRACE. The phase difference varies more among the different models, but in most cases an earlier seasonal storage maximum is shown for the model runs relative to GRACE. There are more basins with phase difference values near zero for LSDM, while WGHM, JSBACH and MPI-HM show large differences with respect to the GRACE result, especially at high latitudes of the Northern Hemisphere (Fig. 3). LSDM explains the GRACE TWS variations relatively better than the other models at most basins (Fig. 4). Only in the Yukon, Nile, Zaire, Yangtze, Indus and the two basins in Australia are explained variances less than $50 \%$. Low values of explained variance also occur at the mid-latitude of the Northern Hemisphere for WGHM. JSBACH and MPI-HM perform generally better at basins in Africa, but have worse results in Siberia. When the annual signal is removed, the explained variances for TWS time series from GRACE and the models are generally less than $60 \%$ (Fig. 5), indicating the models's poor ability to capture the inter-annual variations. LSDM shows especially low explained variance values for many basins in Africa.

The impact from consideration of groundwater to TWS variations in WGHM is investigated by showing the differences of explained variances with and without groundwater (Fig. 6). The positive values indicate that WGHM with groundwater exhibits better agreement with GRACE than the one without. The large impact is mainly located at basins such as Tocantins, Niger, Huang He, Mekong and Mississippi. Only in three basins (Lena, Indus and Yukon) is the effect of groundwater consideration on the model negative.

As each metric usually focuses only on one specific property of statistical performance and has its own limitations, the time series of TWS are given for some basins with the largest deviation between GRACE and the model. We show the Yukon basin, where both WGHM and JSBACH exhibit the largest deviation of annual amplitudes from GRACE. Although the annual amplitude is simulated better by LSDM and MPI-HM, apparent negative phase differences are shown. The Amur basin is also shown, as LSDM,

\section{Explained variance (with - without groundwater)}
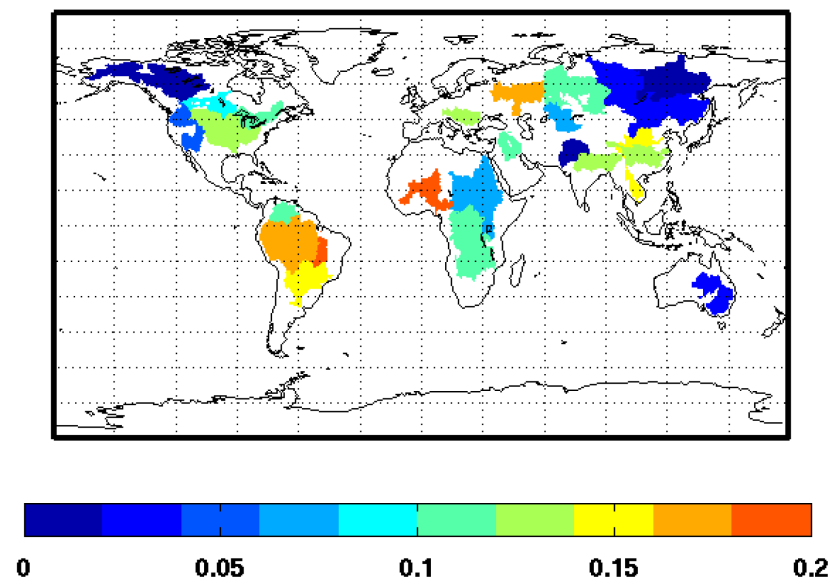

Figure 6. The differences between the explained variance values from WGHM with and without groundwater.

WGHM and MPI-HM all have the largest negative phase differences with GRACE here. Models generally capture the inter-annual signals but perform quite differently among each other and with GRACE in terms of seasonality. Almost opposite phase differences are found for these models. The smallest explained variance for MPI-HM happens at the St. Lawrence basin, where a much larger amplitude and a negative phase difference compared with GRACE are found. When the annual signal is removed, models perform differently in terms of the explained variance. In the Nile basin, large inter-annual variations simulated by LSDM even lead to negative explained variance compared with the other models.

Figure 8 summarizes the overall performance of each statistical metric for all the basins considered by means of box plots. The median $\Delta \mu$ for MPI-HM is almost zero where the other three values are all negative, indicating an underestimation of the annual amplitude of TWS from LSDM, WGHM and JSBACH. As shown in Fig. 2d, MPI-HM overestimates the TWS variations at many basins, which compensate with those underestimated values and lead to a median value at almost zero. All the models have a median phase difference below zero, with LSDM having the smallest bias and range, and MPI-HM the largest bias. This means that the TWS peaks of the models tend to proceed GRACE peaks. For the explained variance, LSDM shows the best median value, followed by WGHM, JSBACH and MPI-HM. However, when the annual signal is removed, many outliers appear in LSDM for the explained variances, while WGHM and MPI-HM show slightly better performances.

We also present the basin-averaged TWS errors from GRACE and the root mean square (rms) differences between TWS variations from GRACE and from the hydrological model runs (Table 2), where the largest and smallest differences are shown in bold and underlined separately. The 
Table 2. Characteristics of the basins shown in Fig. 1. Bold and underlined numbers are the largest and smallest rms differences between GRACE and models separately.

\begin{tabular}{|c|c|c|c|c|c|c|c|c|c|}
\hline \multirow{2}{*}{$\begin{array}{l}\text { Climate } \\
\text { zones }\end{array}$} & \multirow{2}{*}{$\begin{array}{l}\text { Basin } \\
\text { ID }\end{array}$} & \multirow[b]{2}{*}{ Name } & \multirow{2}{*}{$\begin{array}{r}\text { Area } \\
\left(1000 \mathrm{~km}^{2}\right)\end{array}$} & \multicolumn{4}{|c|}{ RMSE $(\mathrm{cm})$ between TWS from GRACE and } & \multirow{2}{*}{$\begin{array}{r}\text { GRACE TWS } \\
\text { Error }(\mathrm{cm})\end{array}$} & \multirow[b]{2}{*}{ SNR } \\
\hline & & & & LSDM & WGHM & JSBACH & MPI-HM & & \\
\hline \multirow{5}{*}{ Tropical } & 1 & Amazon & 5853 & $\underline{4.39}$ & 6.08 & 5.60 & 9.53 & 1.46 & 9.76 \\
\hline & 3 & Zaire & 3699 & $\overline{5.26}$ & 3.36 & $\underline{3.08}$ & 3.49 & 1.32 & 3.82 \\
\hline & 21 & Orinoco & 1039 & 6.37 & $\underline{4.96}$ & 6.21 & 5.79 & 3.14 & 4.74 \\
\hline & 29 & Mekong & 774 & 5.87 & $\overline{5.60}$ & 6.28 & $\underline{4.51}$ & 3.86 & 3.73 \\
\hline & 30 & Tocantins & 769 & 7.69 & 7.49 & $\underline{4.99}$ & $\overline{5.45}$ & 2.81 & 5.95 \\
\hline \multirow{10}{*}{ Dry } & 2 & Nile & 3826 & 4.02 & 1.85 & 1.61 & $\underline{1.39}$ & 1.06 & 3.26 \\
\hline & 10 & Niger & 2240 & 2.53 & 2.97 & $\underline{1.87}$ & 2.23 & 1.29 & 4.93 \\
\hline & 15 & Chari & 1571 & 2.94 & $\underline{1.96}$ & $\overline{2.40}$ & 2.50 & 1.50 & 3.42 \\
\hline & 18 & Indus & 1143 & $\underline{2.17}$ & $\overline{2.61}$ & 3.08 & 3.04 & 1.54 & 2.42 \\
\hline & 19 & Syr-Darya & 1070 & $\underline{2.00}$ & 3.30 & 3.07 & 2.89 & 1.12 & 3.65 \\
\hline & 22 & Murray & 1031 & 3.45 & 3.61 & 3.68 & $\underline{3.38}$ & 1.88 & 2.73 \\
\hline & 23 & Great Artesian & 977 & 2.44 & 2.67 & 2.36 & $\underline{2.22}$ & 1.33 & 2.67 \\
\hline & 24 & Shatt el Arab & 967 & $\underline{2.28}$ & 3.64 & 3.67 & $\overline{2.85}$ & 1.49 & 3.81 \\
\hline & 25 & Huang He & 894 & $\underline{1.52}$ & 2.09 & 1.74 & 2.38 & 1.28 & 2.35 \\
\hline & 27 & Colorado(Ari) & 807 & $\underline{1.90}$ & 2.59 & 2.98 & 2.91 & 1.41 & 2.78 \\
\hline \multirow{5}{*}{ Temperate } & 4 & Mississippi & 3203 & $\underline{1.68}$ & 3.54 & 2.36 & 3.45 & 0.86 & 6.60 \\
\hline & 6 & Parana & 2661 & $\overline{4.17}$ & 3.03 & 3.59 & $\underline{2.81}$ & 1.32 & 4.50 \\
\hline & 11 & Zambezi & 1989 & $\underline{2.89}$ & 7.05 & 4.83 & 3.30 & 1.57 & 6.80 \\
\hline & 12 & Chang Jiang & 1794 & $\overline{2.58}$ & $\underline{2.05}$ & 3.24 & 3.12 & 1.49 & 3.09 \\
\hline & 14 & Ganges & 1628 & 4.04 & $\overline{4.43}$ & 3.73 & $\underline{2.90}$ & 1.94 & 5.99 \\
\hline \multirow{11}{*}{ Cold } & 5 & Amur & 2903 & $\underline{1.20}$ & 1.73 & 1.88 & 2.05 & 0.68 & 3.18 \\
\hline & 7 & Yenisei & 2582 & $\overline{1.89}$ & 2.34 & 3.44 & 3.54 & 0.68 & 6.67 \\
\hline & 8 & $\mathrm{Ob}$ & 2570 & $\overline{1.50}$ & 3.20 & 4.35 & 4.14 & 0.68 & 8.31 \\
\hline & 9 & Lena & 2418 & $\overline{2.33}$ & 2.40 & 3.40 & 3.99 & 0.68 & 6.01 \\
\hline & 13 & Mackenzie & 1713 & 2.67 & 2.83 & 3.95 & 3.39 & 0.83 & 6.20 \\
\hline & 16 & Volga & 1463 & $\underline{2.11}$ & 4.55 & 3.28 & 5.22 & 0.84 & 8.43 \\
\hline & 17 & St. Lawrence & 1267 & $\underline{2.59}$ & 4.74 & 3.42 & 4.88 & 1.14 & 4.94 \\
\hline & 20 & Nelson & 1047 & 1.67 & 3.87 & 3.19 & 3.31 & 1.12 & 3.82 \\
\hline & 26 & Yukon & 852 & $\underline{5.06}$ & 5.72 & 5.74 & 5.29 & 1.19 & 7.68 \\
\hline & 28 & Danube & 788 & $\underline{1.72}$ & 4.18 & 4.03 & 4.27 & 1.50 & 4.96 \\
\hline & 31 & Columbia & 724 & $\overline{2.69}$ & 4.75 & 6.09 & 5.71 & 1.85 & 5.32 \\
\hline
\end{tabular}

basins are grouped according to the Köppen climate zones (Kottek et al., 2006), which include tropical climates, dry climates, temperate climates and cold climates (see Fig. 1). For most of the basins, the GRACE errors are much smaller than the rms differences, which indicates that the main contributions to the differences arise from model uncertainties. Out of the five basins in the tropical zone, three basins have the largest differences between TWS variations from GRACE and models in LSDM. In contrast, WGHM has no largest differences in this climate zone. The smallest value, however, seems to occur randomly among the models. In the dry zone, most basins have low SNR values and the smallest rms of the TWS differences is sometimes quite close to the GRACE TWS errors. For instance, at basins like the Nile, Indus, and the two Australian basins, the GRACE SNR estimates are all below 3 . Thus, it is likely that the large uncertainty in GRACE TWS estimates contributes largely to the bad agreement in these basins. Still, MPI-HM and LSDM perform comparably better, showing a smaller number of largest differences and comparably more smallest differences. In the temperate zone, WGHM has the most largest differences, while MPI-HM has the least. There is, however, no regular pattern of where the smallest difference occurs. In the cold zone, all the smallest differences happen in LSDM, whereas the largest differences mainly occur at MPI-HM and JSBACH.

The performance of the models varies from basin to basin, even within the same climate zone, which could be due to the model structure, parametrization, and also the different water storage components included in TWS. In order to find reasons for the different model performance, we focus on two specific areas that are dominated by snow and arid cli- 
(a) Yukon

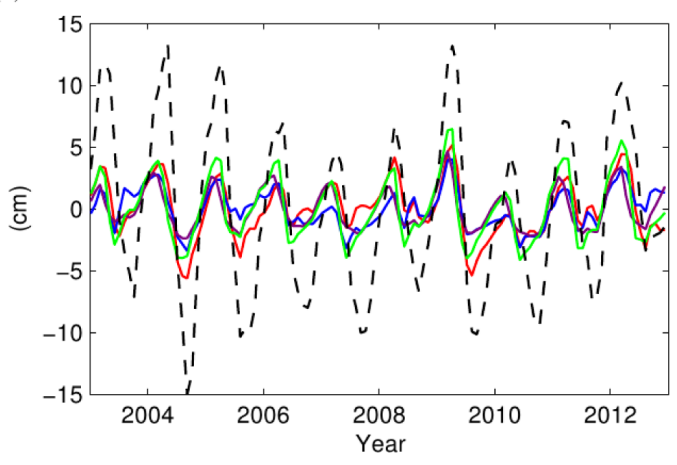

(c) St. Lawrence

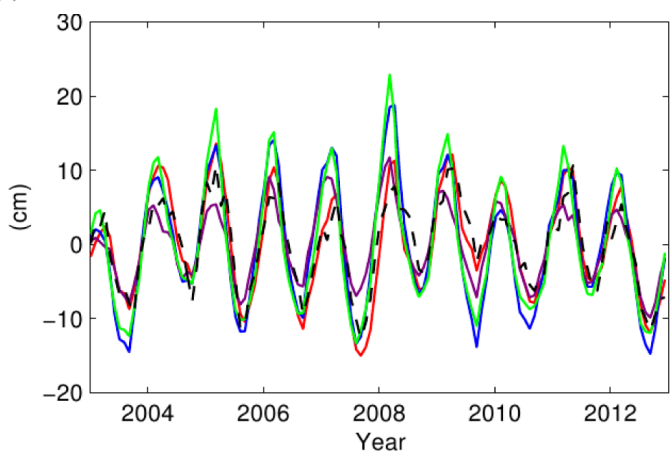

(b) Amur

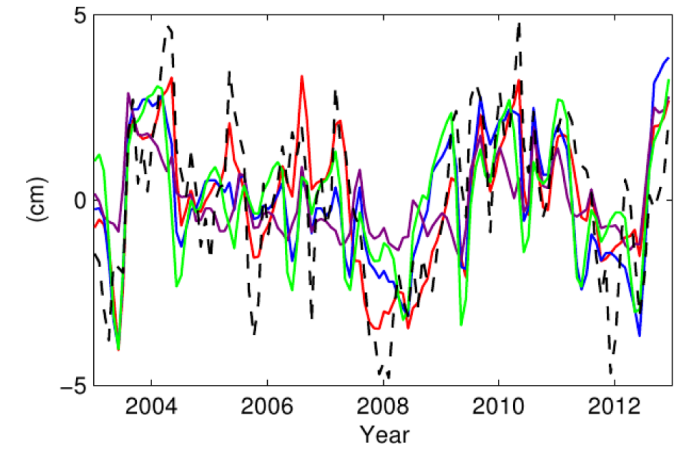

(d) Nile

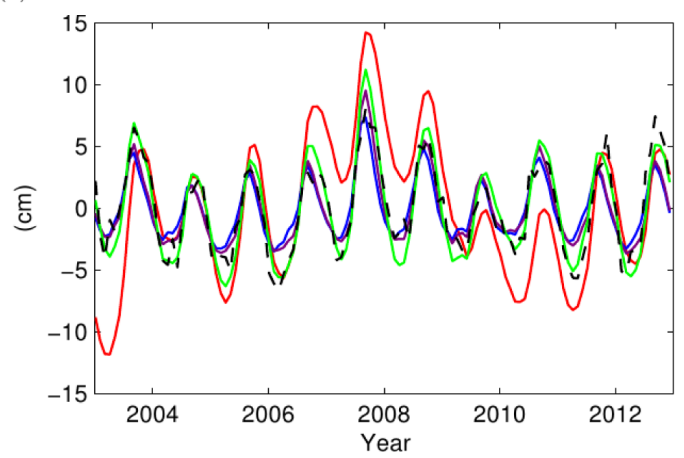

- LSDM - WGHM - JSBACH - MPI-HM - - - GRACE

Figure 7. Examples of monthly TWS time series from GRACE and models for the basins with the largest deviation between model and GRACE in each of the four metrics: relative amplitude differences (Yukon), phase differences (Amur), explained variance (St. Lawrence) and explained variance with annual harmonic signal removed (Nile).

mates in more detail. There, we assess actual evapotranspiration (AET) and runoff which are the main components of the terrestrial water budget and subsequently look into the mean monthly time series of TWS and its individual storage components.

\subsection{Actual evapotranspiration and runoff}

As part of the terrestrial branch of the water cycle, actual evapotranspiration (AET) and runoff may explain part of the differences among the models in terms of storage variations. Although some large differences of AET are present, the effects on subsequently simulated TWS are damped. Especially in humid areas, no direct impact can be found. For arid basins, however, the impact from AET is more dominant. We choose three particularly affected basins (Niger, Chari and Indus) and show the AET time series from all models (Fig. 9). For these basins, the time series comparison shows that the smaller (or larger) AET in the wet season leads to higher (or lower) seasonal amplitude of TWS. In addition, in these dry areas, LSDM generally exhibits enhanced AET due to high temperatures and extremely low humidity which then lead to smaller TWS variations. As exemplarily demon- strated for the Niger basin, the relatively larger AET from LSDM covering the time period 2007 to 2009 is just correspondent to the comparably smaller TWS variations. AET is calculated from the potential evapotranspiration (PET) as a function of the available amount of water. While starting with the same meteorological forcing data, PET is calculated differently by the models using various approaches. PET in the LSDM is calculated by the Thornthwait method, using only the daily temperature and a seasonal heat index that is based on monthly mean temperatures. In WGHM, PET is based on the Priestley-Taylor approach using net radiation, which in turn is computed as a function of incoming shortwave radiation, temperature and surface albedo. For MPIHM, PET is computed in a pre-processing step based on Penman-Montheith using radiation, temperature, wind and humidity. JSBACH computes evaporation based on the energy balance by internally computing atmospheric water demand.

Figure 10 displays time series comparison of runoff from the models for three basins in the tropical zone (Amazon, Orinoco and Mekong). The runoff is calculated from the 
(a)

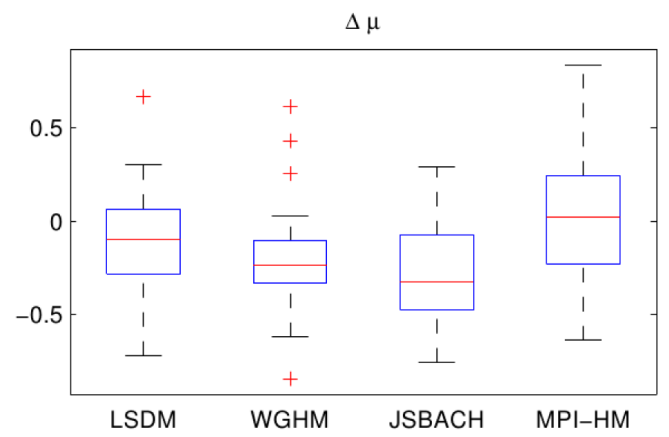

(c)

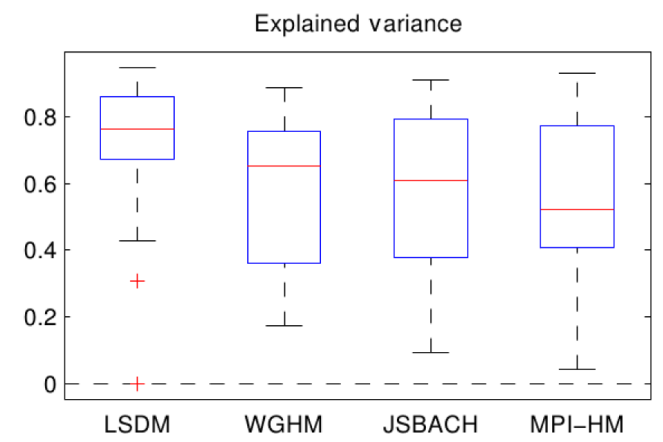

(b)

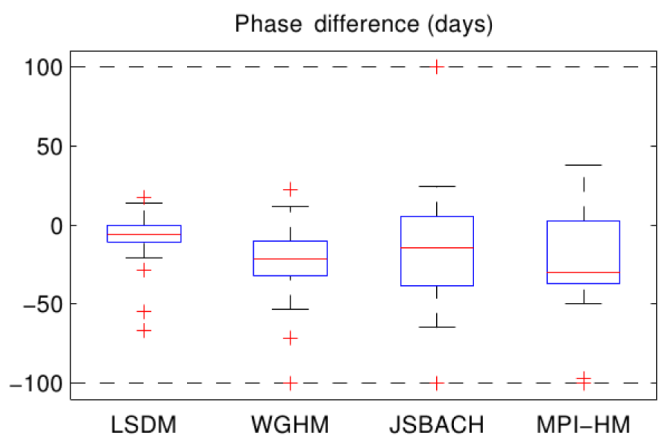

(d)

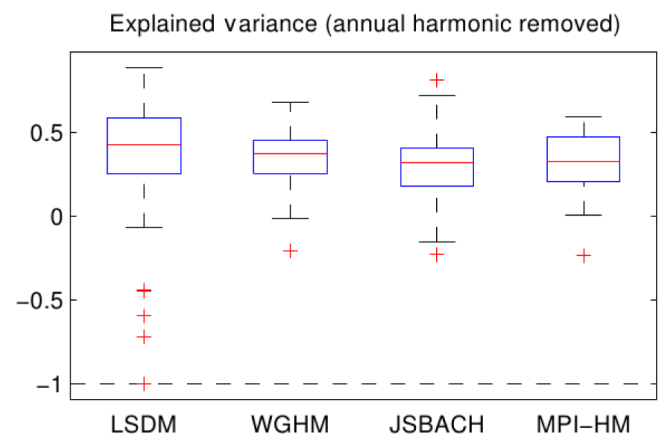

Figure 8. Box plots illustrating the $\Delta \mu$ (a), phase differences (b), explained variance and (c) explained variance with the annual harmonic signal removed (d) for the TWS from GRACE and models. The red horizontal line is the median, the edges of the box are the 25th and 75th percentiles, the whiskers extend to the most extreme data points not considered outliers, and outliers are plotted individually and set within the extreme data limits as indicated by the dashed line.

models following the equation

$R(t)=P(t)-\mathrm{ET}(t)-\operatorname{TWSC}(t)$,

where $t$ is the time, $P$, ET and $R$ are the basin-averaged precipitation, evapotranspiration and runoff, and TWSC is the terrestrial water storage change (Ramillien et al., 2006). It is seen that the performance of a certain model is connected with its differently simulated runoff. At the Amazon basin, the comparably large runoff simulated from MPI-HM also leads to smaller variability in TWS, which is also shown at the Orinoco basin. At the Mekong basin, the larger amplitude in TWS from JSBACH compared with GRACE is related to the apparently small amplitude in its runoff.

\subsection{Snow-dominated catchments}

As highlighted in Sect. 3.2, models perform quite differently at high latitudes of the Northern Hemisphere (cold zone), which are generally dominated by snow. Especially JSBACH and MPI-HM show large differences in the TWS when compared with GRACE. We focus here on four basins in this area, Lena, Yenisei, Ob and Yukon, and look into the mean monthly time series of the TWS and its different components (Fig. 11). For LSDM and MPI-HM, subsurface water only includes the water storage in the root zone, while for WGHM and JSBACH, both root zone and deep layer water storage are included. LSDM and WGHM show the smallest phase differences with GRACE in terms of TWS, while the other two exhibit negative phase shifts. The subsurface water variations from WGHM and LSDM have very similar patterns, with an apparent peak usually in May. The phases of the snow water time series from LSDM and WGHM are also quite close, but LSDM always has a slightly larger amplitude. Since the two use the same snow scheme (degree-day method), this is certainly related to the different model parameters or sub-grid representation schemes. The surface water storage from these two models are sometimes different. For the Ob River, for instance, the different surface water storage also leads to the poor performance of WGHM in terms of TWS when compared with GRACE. The snow variations from LSDM and MPI-HM are almost identical to each other. However, the different subsurface and surface water simulated by MPI-HM causes a bad timing of the TWS peaks. For the Lena basin, although the snow variations from LSDM, WGHM and MPIHM are quite close, MPI-HM simulates almost no surface water variations, which leads to a poor agreement of TWS with GRACE estimates. For JSBACH, there is already a large phase difference in the snow storage, which is mainly due to the poor capture of the phase of the snow accumulation and onset of melting. This could be caused by the specific snow 
(a) Niger
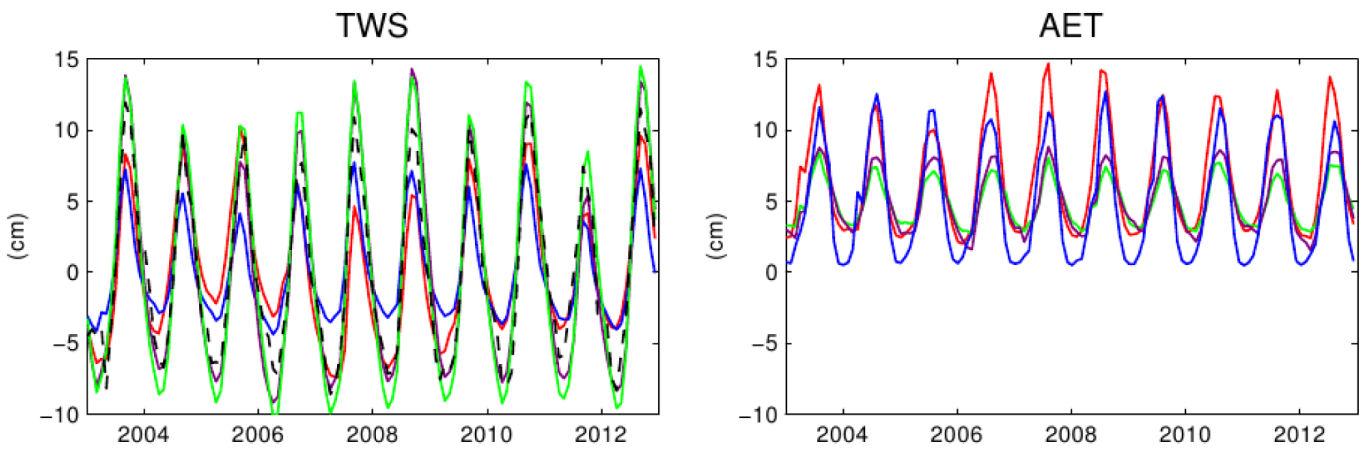

(b) Chari
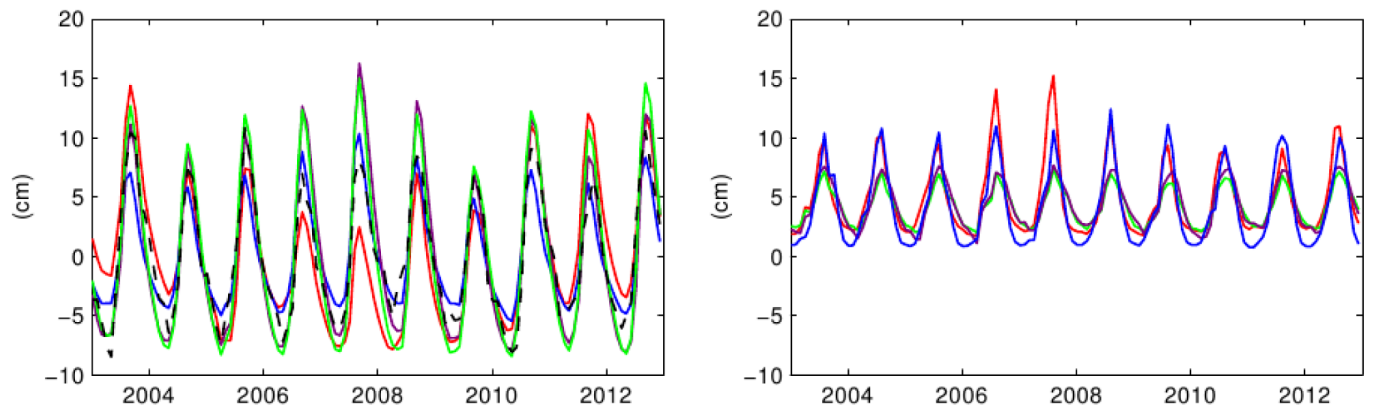

(c) Indus
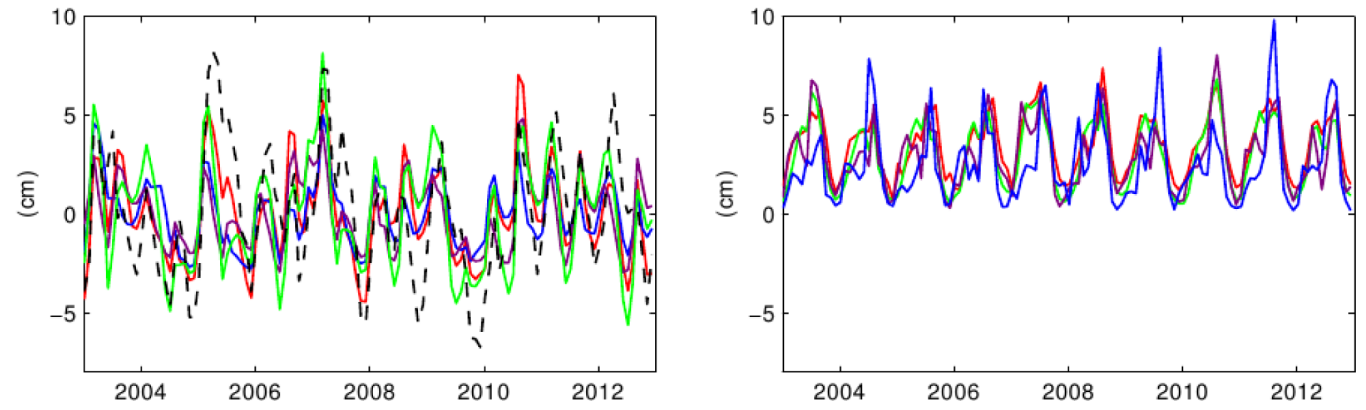

- LSDM — WGHM — JSBACH - MPI-HM - - - GRACE

Figure 9. Time series of TWS (left) from GRACE and models and model-simulated AET time series (right), each for three different catchments in the dry zone: Niger, Chari, and Indus.

scheme applied by JSBACH. Yukon, however, is quite different from the other snow-dominated basins. Here, all the models underestimate the annual amplitude of TWS when compared with GRACE. Since the basin-average TWS error from GRACE at Yukon is $1.19 \mathrm{~cm}$ and much smaller than the discrepancies between GRACE and the models (Table 2), it could be the case that all models fail to represent certain hydrological processes, or that our GRACE TWS errors are too optimistic here since the re-scaling errors are also estimated from a hydrological model ensemble. In addition, Seo et al. (2006) found also large TWS errors at Yukon basin and suggested that the atmosphere and ocean tidal and non-tidal de-aliasing errors might be a problem in this area. Investigating those discrepancies in full detail, however, is beyond the scope of our present paper and will be left open for future study.

\subsection{Dry catchments}

We also focus on four catchments in the dry zone, which are characterized by annual precipitation lower than annual potential evapotranspiration (McKnight and Hess, 2000). For the Nile and Niger basins, the subsurface water is the main 
(a) Amazon
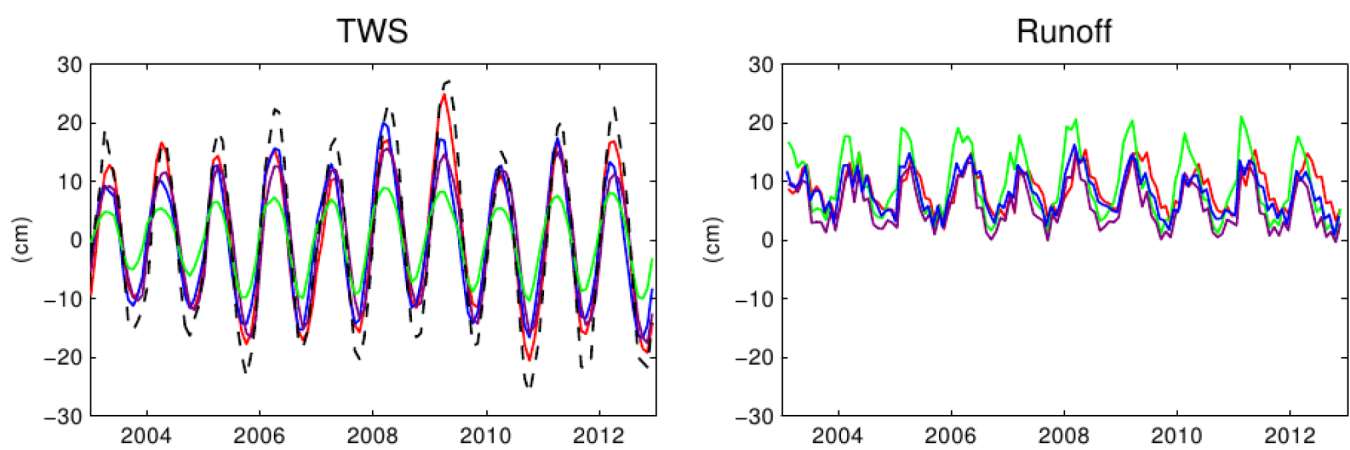

(b) Orinoco
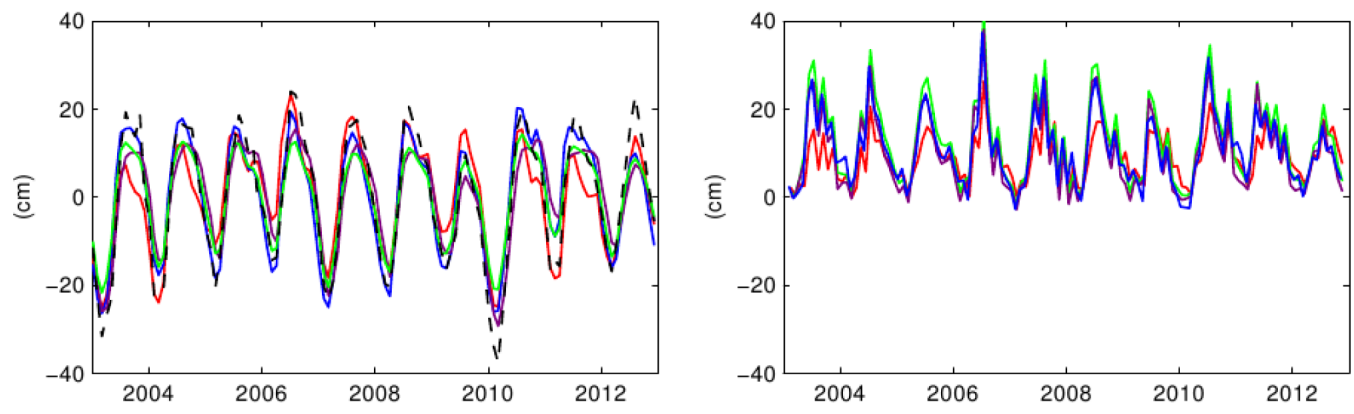

(c) Mekong
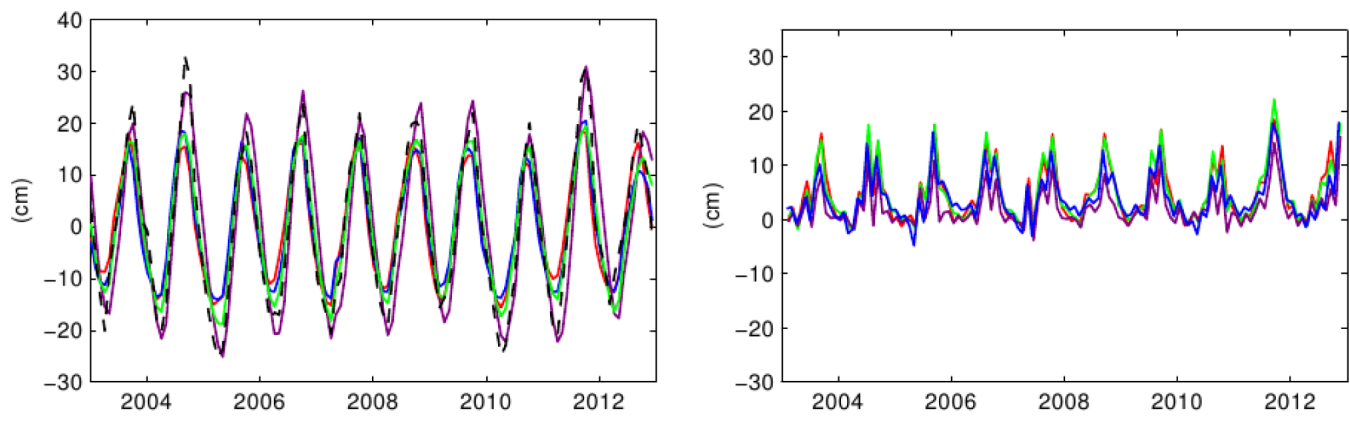

- LSDM — WGHM —JSBACH - MPI-HM - - - GRACE

Figure 10. Time series of TWS (left) from GRACE and models and model-simulated runoff time series (right), each for three different catchments in the tropical zone: Amazon, Orinoco, and Mekong.

contributor to the TWS changes (Fig. 12). The TWS variations from JSBACH and MPI-HM show a quite similar annual cycle when compared to GRACE. MPI-HM generally exhibits a larger amplitude in simulated subsurface water and TWS. WGHM deviates considerably with a much smaller amplitude and a large phase shift in the subsurface water. The simulated surface water from WGHM brings TWS slightly closer to that from GRACE. LSDM, however, performs differently in these two basins. In the Nile basin, although the subsurface water from LSDM is consistent with JSBACH and MPI-HM, the simulated surface water variations lead to a higher amplitude of TWS variations when compared with
GRACE. In Niger, LSDM performs quite closely to WGHM, but with a slightly larger amplitude. All models tend to perform poorly in terms of TWS when compared with GRACE in the Indus basin. We note a comparably low SNR $(2.2 \mathrm{~cm})$ for the GRACE estimated TWS here, which is mainly contributed by the large leakage error at this basin (Zhang et al., 2016). In addition, the Indus basin is not only subject to large-scale groundwater depletion from intensive irrigation, but is also affected by snow melting and glacier melting from Himalaya. Here, the subsurface water simulated by the models already shows large discrepancies. As in other basins affected by snow dynamics, JSBACH also fails to capture the 
(a) $\mathrm{Ob}$
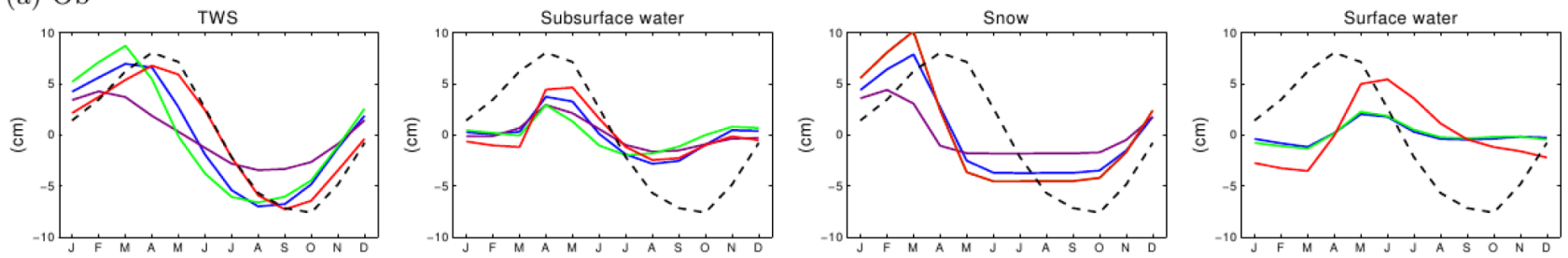

(b) Lena
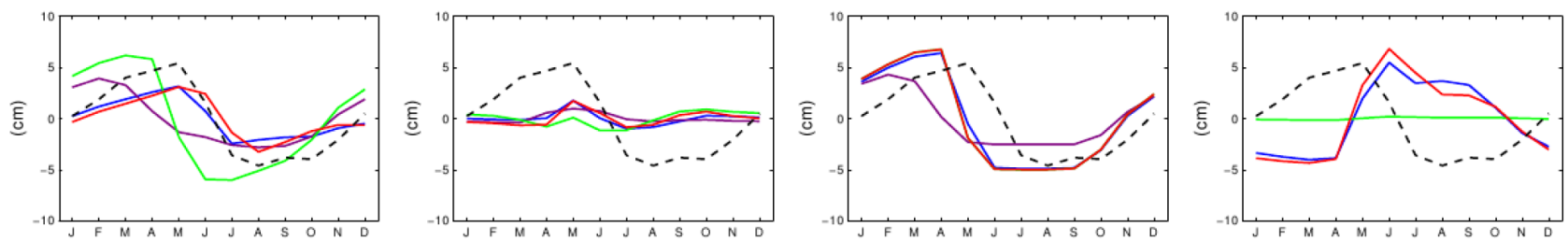

(c) Yenizei
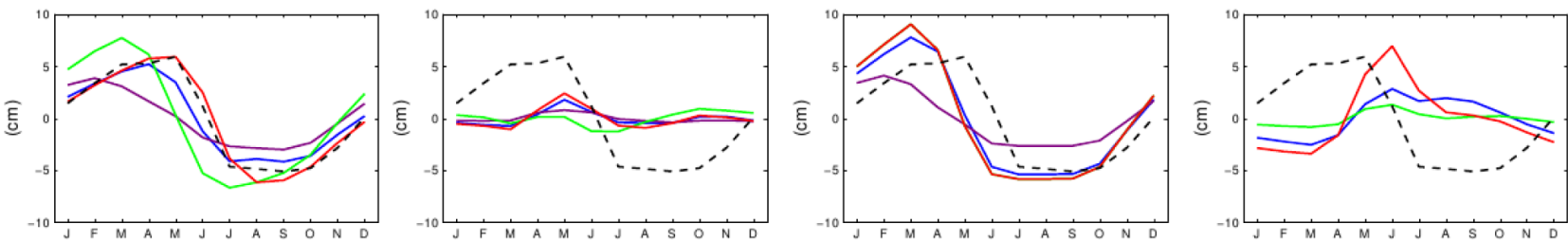

(d) Yukon
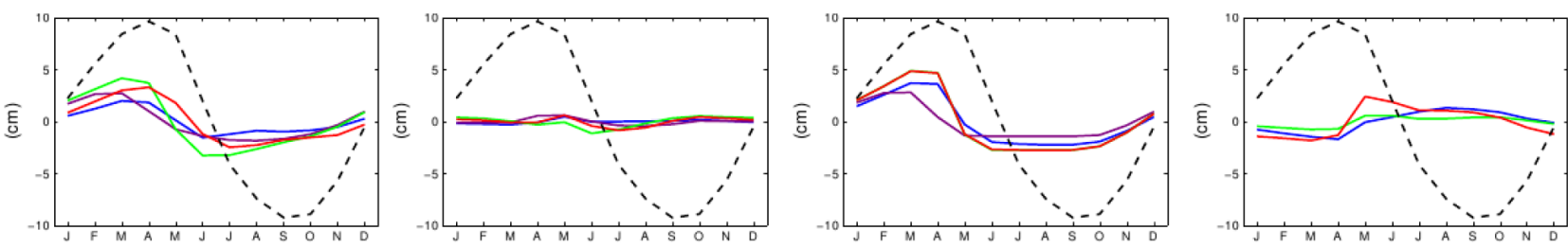

$$
\text { LSDM — WGHM —JSBACH }- \text { MPI-HM - - - GRACE }
$$

Figure 11. Mean monthly time series of TWS (first column) and the individual storage contributions from subsurface water (second column), snow water equivalent (third column) and surface water (fourth column), each for four snowy catchments: Ob, Lena, Yenizei and Yukon. TWS from GRACE (dashed line) has been included in every sub-figure for reference.

snow variations properly. MPI-HM performs poorly in simulating the surface water, with a delayed dynamics which leads to a preceded annual cycle. At the Huang He basin, the subsurface water from LSDM, WGHM and JSBACH as the main contributors to the TWS show similar annual variations to GRACE, while MPI-HM has a much larger amplitude. The surface water, however, is simulated differently by LSDM and WGHM, which consequently leads to different TWS variations.

\section{Summary}

We validate TWS variations simulated by four different global hydrological models with monthly GRACE gravity data. All the models are forced with the same WFDEI meteorological data set to exclude the effect of meteorological forcing on the models. Four statistical metrics focusing on different aspects of model performance compared with GRACE have been applied. In addition, time series of TWS variations from GRACE and models are investigated, where different water storage components from models are shown as well. 
(a) Nile
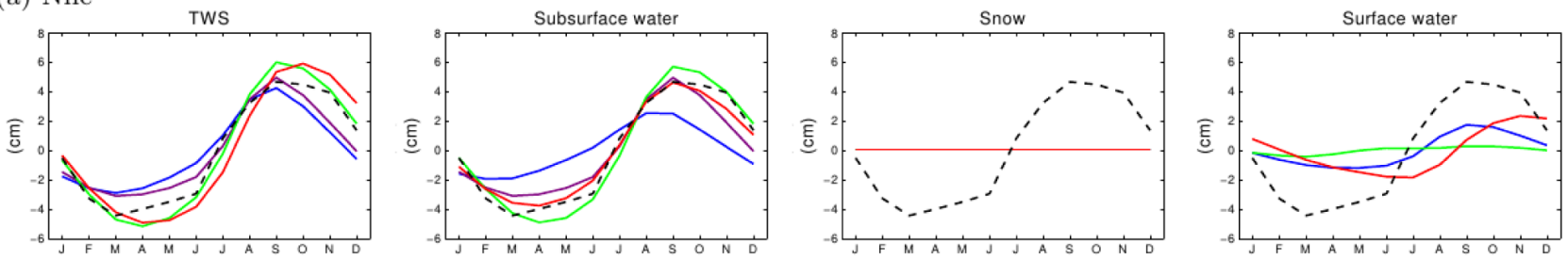

(b) Niger
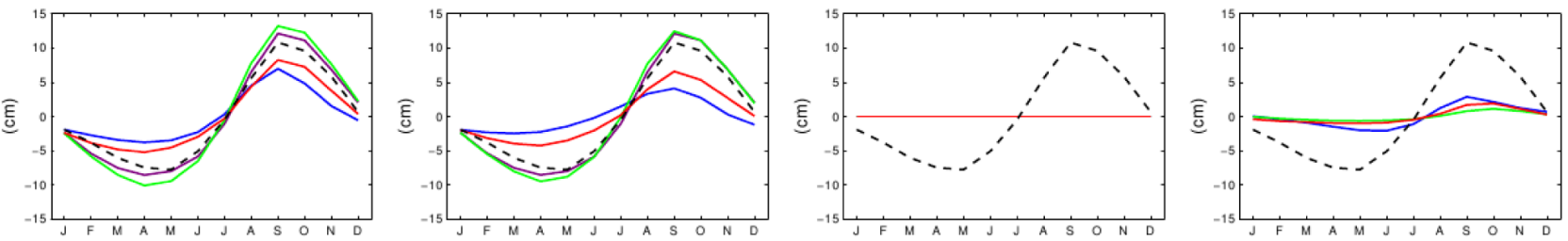

(c) Indus
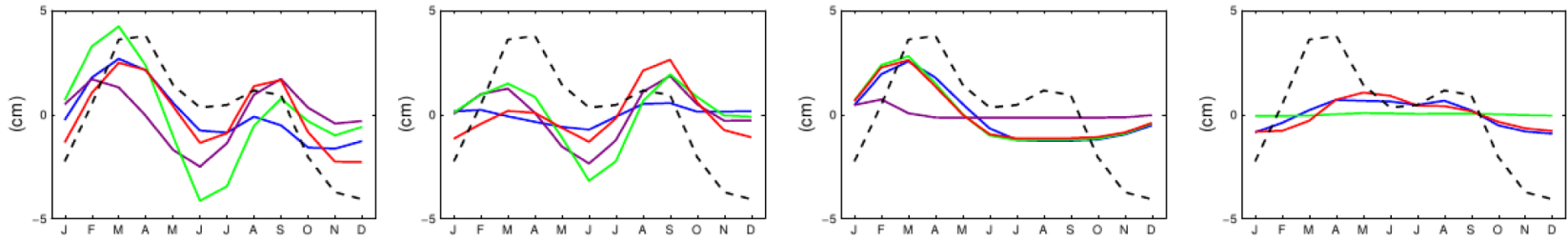

(d) Huang He
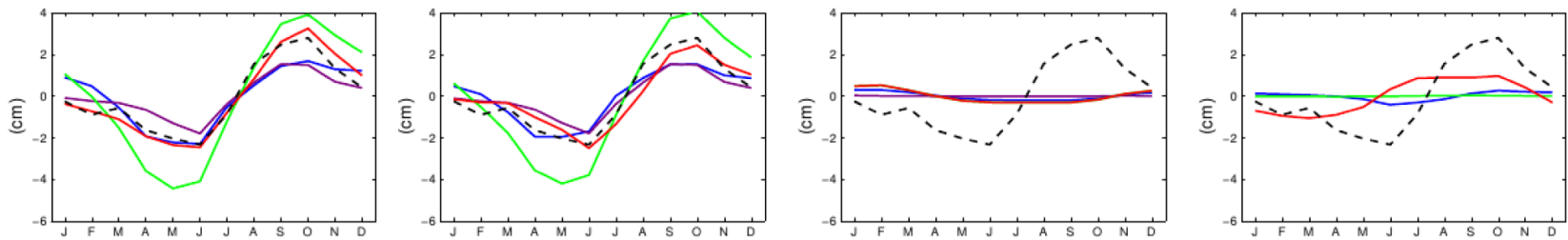

$\longrightarrow$ LSDM $\longrightarrow$ WGHM $\longrightarrow$ JSBACH $\longrightarrow$ MPI-HM - - - GRACE

Figure 12. Mean monthly time series of TWS (first column) and the individual storage contributions from subsurface water (second column), snow water equivalent (third column) and surface water (fourth column), each for four dry catchments: Nile, Niger, Indus and Huang He. TWS from GRACE (black line) has been included in every sub-figure for reference.

At certain basins like the Danube, Tocantins, Columbia, Ganges, Mekong, and Amazon, all numerical models show good agreement with GRACE. However, models still perform quite differently at many other basins, even though forced with the same meteorological data set. At the Nile, Indus, Murray and Great Artesian basins, large TWS errors and low SNR are found, which suggests a major contribution from GRACE errors to the differences. A good capture of annual amplitude and phase at most basins leads to high values of explained variance in many basins for LSDM. However, serious problems are also found in the same model run in some central Africa basins, like the Nile and Zaire, where TWS simulated by LSDM exhibits unusual large inter-annual variations. WGHM performs generally well in tropical and cold regions, but rather poorly in the temperate zone. JSBACH and MPI-HM show large discrepancies with GRACE at the basins at high latitudes of the Northern Hemisphere.

Model performance is also investigated in some snowdominated and dry catchments in more detail through time series comparison. The poor performance of JSBACH and MPI-HM in snow-dominated regions is mainly related to negative phase shifts compared to GRACE. MPI-HM simulates identical snow variations to LSDM; however, the different simulations of subsurface water and especially surface water still lead to different TWS variations in snowdominated regions. Despite the missing surface water com- 
ponent, the simulated snow variations in JSBACH already show smaller amplitude and negative phase differences compared with all the other models. This could be related to the fact that JSBACH simulates snow in a more physical way based on energy balance, which is totally different from the degree-day method applied by all the other models. The comparably better agreement of LSDM and WGHM with GRACE in terms of TWS in these snow-dominated basins is partly caused by the realistic surface water component represented by these two models. In the dry catchments, the impact from AET on TWS is relatively strong. The smaller AET from MPI-HM also leads to better agreement with GRACE, whereas LSDM shows large differences with GRACE in terms of TWS, especially at some dry basins in central Africa, partly due to the overly simple evaporation scheme. PET is simulated using a superior parametrization by MPIHM, while LSDM still applies the traditional Thornthwaite method based solely on air temperature. The groundwater considered by WGHM also has some impact on the simulated TWS, especially at basins such as Tocantins, Mekong, Niger and Mississippi. At the Yukon basin, we found the bad performance of all models in terms of TWS when compared with GRACE, which could be due to the effects of atmospheric and oceanic de-aliasing errors not further discussed in our current study. In future, we would like to assess all possible errors of GRACE TWS through investigation of simulated GRACE-type gravity field time series (Flechtner et al., 2016) based on realistic orbits and instrument error assumptions as well as background error assumptions out of the updated ESA Earth system model (Dobslaw et al., 2015, 2016), which we believe will further help to explain the discrepancy between global models of the terrestrial water cycle and GRACE satellite observations.

\section{Data availability}

GRACE data at different processing levels are publicly available via ftp://isdcftp.gfz-potsdam.de/grace/ (Dahle et al., 2012). Post-processed TWS data based on GRACE sensor data are moreover accessible via the interactive web interface http://icgem.gfz-potsdam.de/ICGEM/JSB/ G3Browser-st.html (Zhang et al., 2016).

Competing interests. The authors declare that they have no conflict of interest.

Acknowledgements. This study has been supported by the German Federal Ministry of Education and Research within the FONA research program under grants 03F0654A and 01LP1151A.

The article processing charges for this open-access publication were covered by a Research

Centre of the Helmholtz Association.
Edited by: W. Buytaert

Reviewed by: two anonymous referees

\section{References}

Bergmann-Wolf, I., Zhang, L., and Dobslaw, H.: Global eustatic sea-level variations for the approximation of geocenter motion from GRACE, J. Geod. Sci., 4, 37-48, doi:10.2478/jogs-20140006, 2014.

Biancale, R. and Bode, A.: Mean annual and seasonal atmospheric tide models based on 3-hourly and 6-hourly ECMWF surface pressure data, Scientific Technical Report STR06/01, GFZ, Helmholtz-Zentrum, Potsdam, doi:10.2312/GFZ.b10306011, 2006.

Bierkens, M. F. P. and van den Hurk, B. J. J. M.: Groundwater convergence as a possible mechanism for multi-year persistence in rainfall, Geophys. Res. Lett., 34, L02402, doi:10.1029/2006GL028396, 2007.

Brovkin, V., Raddatz, T., Reick, C. H., Claussen, M., and Gayler, V.: Global biogeophysical interactions between forest and climate, Geophys. Res. Lett., 36, L07405, doi:10.1029/2009GL037543, 2009.

Chen, J. L., Wilson, C. R., and Tapley, B. D.: The 2009 exceptional Amazon flood and interannual terrestrial water storage change observed by GRACE, Water Resour. Res., 46, w12526, doi:10.1029/2010WR009383, 2010.

Dahle, C., Flechtner, F., Gruber, C., König, D., König, R., Michalak, G., and Neumayer, K.: GFZ GRACE Level-2 Processing Standards Document for Level-2 Product Release 0005, Scientific technical report-data, GFZ, Helmholtz-Zentrum, Potsdam, Potsdam, doi:10.2312/GFZ.b103-1202-25, 2012 (data available at: ftp://isdcftp.gfz-potsdam.de/grace/).

Dahle, C., Flechtner, F., Gruber, C., König, D., König, R., Michalak, G., and Neumayer, K.-H.: GFZ RL05: An Improved TimeSeries of Monthly GRACE Gravity Field Solutions, in: Observation of the System Earth from Space - CHAMP, GRACE, GOCE and future missions, edited by: Flechtner, F., Sneeuw, N., and Schuh, W.-D., Advanced Technologies in Earth Sciences, 29-39, Springer Berlin Heidelberg, doi:10.1007/978-3-642-32135-1_4, 2014.

Dee, D. P., Uppala, S. M., Simmons, A. J., Berrisford, P., Poli, P., Kobayashi, S., Andrae, U., Balmaseda, M. A., Balsamo, G., Bauer, P., Bechtold, P., Beljaars, A. C. M., van de Berg, L., Bidlot, J., Bormann, N., Delsol, C., Dragani, R., Fuentes, M., Geer, A. J., Haimberger, L., Healy, S. B., Hersbach, H., Hólm, E. V., Isaksen, L., Kållberg, P., Köhler, M., Matricardi, M., McNally, A. P., Monge-Sanz, B. M., Morcrette, J.-J., Park, B.-K., Peubey, C., de Rosnay, P., Tavolato, C., Thépaut, J.-N., and Vitart, F.: The ERA-Interim reanalysis: configuration and performance of the data assimilation system, Q. J. Roy. Meteor., 137, 553-597, doi:10.1002/qj.828, 2011.

Dill, R.: Hydrological model LSDM for operational Earth rotation and gravity field variations, GFZ Scientific Technical ReportSTR08/09, GFZ, Helmholtz-Zentrum, Potsdam, Potsdam, 2008.

Dill, R. and Dobslaw, H.: Short-term polar motion forecasts from earth system modeling data, J. Geodesy, 84, 529-536, doi:10.1007/s00190-010-0391-5, 2010. 
Dill, R. and Dobslaw, H.: Numerical simulations of global-scale high-resolution hydrological crustal deformations, J. Geophys. Res.: B, 118, 5008-5017, doi:10.1002/jgrb.50353, 2013.

Dirmeyer, P. A.: A history and review of the global soil wetness project (GSWP), J. Hydrometeor, 12, 729-749, doi:10.1175/JHM-D-10-05010.1, 2011.

Dirmeyer, P. A., Gao, X., Zhao, M., Guo, Z., Oki, T., and Hanasaki, N.: GSWP-2: Multimodel analysis and implications for our perception of the land surface, B. Am. Meteor. Soc., 87, 1381-1397, doi:10.1175/BAMS-87-10-1381, 2006.

Dobslaw, H., Dill, R., Grötzsch, A., Brzeziński, A., and Thomas, M.: Seasonal polar motion excitation from numerical models of atmosphere, ocean, and continental hydrosphere, J. Geophys. Res.: B, 115, B10406, doi:10.1029/2009JB007127, 2010.

Dobslaw, H., Flechtner, F., Bergmann-Wolf, I., Dahle, C., Dill, R., Esselborn, S., Sasgen, I., and Thomas, M.: Simulating highfrequency atmosphere-ocean mass variability for dealiasing of satellite gravity observations: AOD1B RL05, J. Geophys. Res.Oceans, 118, 3704-3711, doi:10.1002/jgrc.20271, 2013.

Dobslaw, H., Bergmann-Wolf, I., Dill, R., Forootan, E., Klemann, V., Kusche, J., and Sasgen, I.: The updated ESA Earth System Model for future gravity mission simulation studies, J. Geodesy, 89, 505-513, doi:10.1007/s00190-014-0787-8, 2015.

Dobslaw, H., Bergmann-Wolf, I., Forootan, E., Dahle, C., MayerGürr, T., Kusche, J., and Flechtner, F.: Modeling of presentday atmosphere and ocean non-tidal de-aliasing errors for future gravity mission simulations, J. Geodesy, 90, 423-436, doi:10.1007/s00190-015-0884-3, 2016.

Döll, P., Kaspar, F., and Lehner, B.: A global hydrological model for deriving water availability indicators: model tuning and validation, J. Hydrol., 270, 105-134, doi:10.1016/S00221694(02)00283-4, 2003.

Flechtner, F., Neumayer, K.-H., Dahle, C., Dobslaw, H., Fagiolini, E., Raimondo, J.-C., and Güntner, A.: What Can be Expected from the GRACE-FO Laser Ranging Interferometer for Earth Science Applications?, Surveys in Geophysics, 37, 453-470, doi:10.1007/s10712-015-9338-y, 2016.

Gudmundsson, L., Wagener, T., Tallaksen, L. M., and Engeland, K.: Evaluation of nine large-scale hydrological models with respect to the seasonal runoff climatology in Europe, Water Resour. Res., 48, W11504, doi:10.1029/2011WR010911, 2012.

Haddeland, I., Clark, D. B., Franssen, W., Ludwig, F., Voß, F., Arnell, N. W., Bertrand, N., Best, M., Folwell, S., Kabat, P., Koirala, S., Oki, T., Polcher, J., Stacke, T., Viterbo, P., Weedon, G. P., Yehm, P., Gerten, D., Gomes, S., Gosling, S. N., Hagemann, S., Hanasaki, N., Harding, R., and Heinke, J.: Multimodel estimate of the global terrestrial water balance: Setup and first results, J. Hydrometeor, 12, 869-884, doi:10.1175/2011JHM1324.1, 2011.

Hagemann, S. and Gates, L.: Validation of the hydrological cycle of ECMWF and NCEP reanalyses using the MPI hydrological discharge model, J. Geophys. Res., 106, 1503-1510, doi:10.1029/2000JD900568, 2001.

Hagemann, S. and Gates, L.: Improving a subgrid runoff parameterization scheme for climate models by the use of high resolution data derived from satellite observations, Clim. Dyn., 21, 349359, doi:10.1007/s00382-003-0349-x, 2003.

Hirschi, M., Seneviratne, S., and Schär, C.: Seasonal variations in terrestrial water storage for major midlatitude river basins, J. Hydrometeor, 7, 39-60, doi:10.1175/JHM480.1, 2006.
Hunger, M. and Döll, P.: Value of river discharge data for globalscale hydrological modeling, Hydrol. Earth Syst. Sci., 12, 841861, doi:10.5194/hess-12-841-2008, 2008.

Jungclaus, J. H., Fischer, N., Haak, H., Lohmann, K., Marotzke, J., Matei, D., Mikolajewicz, U., Notz, D., and von Storch, J. S.: Characteristics of the ocean simulations in the Max Planck Institute Ocean Model (MPIOM) the ocean component of the MPI-Earth system model, JAMES, 5, 422-446, doi:10.1002/jame.20023, 2013.

Koster, R. D., Dirmeyer, P. A., Guo, Z., Bonan, G., Chan, E., Cox, P., Gordon, C. T., Kanae, S., Kowalczyk, E., Lawrence, D., Liu, P., Lu, C.-H., Malyshev, S., McAvaney, B., Mitchell, K., Mocko, D., Oki, T., Oleson, K., Pitman, A., Sud, Y. C., Taylor, C. M., Verseghy, D., Vasic, R., Xue, Y., and Yamada, T.: Regions of strong coupling between soil moisture and precipitation, Science, 305, 1138-1140, doi:10.1126/science.1100217, 2004.

Kottek, M., Grieser, J., Beck, C., Rudolf, B., and Rubel, F.: World Map of the Köppen-Geiger climate classification updated, Meteorol. Z., 15, 259-263, doi:10.1127/0941-2948/2006/0130, 2006.

Kusche, J.: Approximate decorrelation and non-isotropic smoothing of time-variable GRACE-type gravity field models, J. Geodesy, 81, 733-749, doi:10.1007/s00190-007-0143-3, 2007.

Kusche, J., Schmidt, R., Petrovic, S., and Rietbroek, R.: Decorrelated GRACE time-variable gravity solutions by GFZ, and their validation using a hydrological model, J. Geodesy, 83, 903-913, doi:10.1007/s00190-009-0308-3, 2009.

Landerer, F. W. and Swenson, S. C.: Accuracy of scaled GRACE terrestrial water storage estimates, Water Resour. Res., 48, W04531, doi:10.1029/2011WR011453, 2012.

Leblanc, M. J., Tregoning, P., Ramillien, G., Tweed, S. O., and Fakes, A.: Basin-scale, integrated observations of the early $21 \mathrm{st}$ century multiyear drought in southeast Australia, Water Resour. Res., 45, w04408, doi:10.1029/2008WR007333, 2009.

McKnight, T. L. and Hess, D.: Climate zones and types: Climate Zones and Types, Physical geography: A landscape appreciation, Upper Saddle River, NJ: Prentice Hall, 223-226, 2000.

Meehl, G. A., Goddard, L., Murphy, J., Stouffer, R. J., Boer, G., Danabasoglu, G., Dixon, K., Giorgetta, M. A., Greene, A. M., Hawkins, E., Hegerl, G., Karoly, D., Keenlyside, N., Kimoto, M., Kirtman, B., Navarra, A., Pulwarty, R., Smith, D., Stammer, D., and Stockdale, T.: Decadal prediction. Can it be skillful?, B. Am. Meteor. Soc., 90, 1467-1485, 2009.

Müller Schmied, H., Eisner, S., Franz, D., Wattenbach, M., Portmann, F. T., Flörke, M., and Döll, P.: Sensitivity of simulated global-scale freshwater fluxes and storages to input data, hydrological model structure, human water use and calibration, Hydrol. Earth Syst. Sci., 18, 3511-3538, doi:10.5194/hess-18-35112014, 2014.

Petit, G. and Luzum, B.: IERS Conventions (2010), IERS Technical Note; 36, Bundesamt für Kartographie und Geodäsie, Frankfurt am Main, 2010.

Raddatz, T. J., Reick, C. H., Knorr, W., Kattge, J., Roeckner, E., Schnur, R., Schnitzler, K. G., Wetzel, P., and Jungclaus, J.: Will the tropical land biosphere dominate the climate-carbon cycle feedback during the twenty-first century?, Clim. Dyn., 29, 565574, doi:10.1007/s00382-007-0247-8, 2007.

Ramillien, G., Frappart, F., Gäntner, A., Ngo-Duc, T., Cazenave, A., and Laval, K.: Time variations of the regional evapotranspiration rate from Gravity Recovery and Climate Experiment 
(GRACE) satellite gravimetry, Water Resour. Res., 42, w10403, doi:10.1029/2005WR004331, 2006.

Rodell, M., McWilliams, E. B., Famiglietti, J. S., Beaudoing, H. K., and Nigro, J.: Estimating evapotranspiration using an observation based terrestrial water budget, Hydrol. Process., 25, 4082-4092, doi:10.1002/hyp.8369, 2011.

Savcenko, R. and Bosch, W.: EOT11a - Empirical ocean tide model from multi-mission satellite altimetry, DGFI Report No. 89, Deutsches Geodätisches Forschungsinstitut (DGFI), München, 2012.

Schewe, J., Heinke, J., Gerten, D., Hadeland, I., Arnell, N. W., Clark, D. B., Dankers, R., Eisner, S., Fekete, B. M., ColónGonzález, F. J., Gosling, S. N., Kim, H., Liu, X. C., Masaki, Y., Portmann, F. T., Satoh, Y., Stacke, T., Tang, Q. H., Wada, Y., Wisser, D., Albrecht, T., Frieler, K., Pointek, F., Warszawski, L., and Kabat, P.: Multimodel assessment of water scarcity under climate change, P. Natl. Acad. Sci., 111, 3245-3250, doi:10.1073/pnas.1222460110, 2014.

Seneviratne, S., Viterbo, P., and C. Schär, D. L.: Inferring changes in terrestrial water storage using ERA-40 reanalysis data: the Mississippi River basin, J. Climate, 17, 2039-2057, 2004.

Seneviratne, S. I. and Stöckli, R.: The role of land-atmosphere interactions for climate variability in Europe, vol. 33 of Advances in Global Change Research, Springer Netherlands, doi:10.1007/978-1-4020-6766-2_12, 2007.

Seo, K.-W., Wilson, C. R., Famiglietti, J. S., Chen, J. L., and Rodell, M.: Terrestrial water mass load changes from Gravity Recovery and Climate Experiment (GRACE), Water Resour. Res., 42, w05417, doi:10.1029/2005WR004255, 2006.

Stacke, T. and Hagemann, S.: Development and evaluation of a global dynamical wetlands extent scheme, Hydrol. Earth Syst. Sci., 16, 2915-2933, doi:10.5194/hess-16-2915-2012, 2012.

Stevens, B., Giorgetta, M., Esch, M., Mauritsen, T., Crueger, T., Rast, S., Salzmann, M., Schmidt, H., Bader, J., Block, K., Brokopf, R., Fast, I., Kinne, S., Kornblueh, L., Lohmann, U., Pincus, R., Reichler, T., and Roeckner, E.: Atmospheric component of the MPI-M Earth System Model: ECHAM6, JAMES, 5, 146-172, doi:10.1002/jame.20015, 2013.
Tang, Q., Gao, H., Yeh, P., Oki, T., Su, F., and Lettenmaier, D.: Dynamics of terrestrial water storage change from satellite and surface observations and modeling, J. Hydrometeor, 13, 156-170, 2010.

Tapley, B. D., Bettadpur, S., Watkins, M., and Reigber, C.: The gravity recovery and climate experiment: Mission overview and early results, Geophys. Res. Lett., 31, L09607, doi:10.1029/2004GL019920, 2004.

Wahr, J.: Time-variable gravity from satellites, vol. 3, Elsevier, 2009.

Wahr, J., Swenson, S., Zlotnicki, V., and Velicogna, I.: Timevariable gravity from GRACE: First results, Geophys. Res. Lett., 31, L11501, doi:10.1029/2004GL019779, 2004.

Weedon, G. P., Gomes, S., Viterbo, P., Shuttleworth, W. J., Blyth, E., Österle, H., Adam, J. C., Bellouin, N., Boucher, O., and Best, M.: Creation of the WATCH forcing data and its use to assess global and regional reference crop evaporation over land during the twentieth century, J. Hydrometeor., 12, 823-848, doi:10.1175/2011JHM1369.1, 2011.

Weedon, G. P., Balsamo, G., Bellouin, N., Gomes, S., Best, M. J., and Viterbo, P.: The WFDEI meteorological forcing data set: WATCH Forcing Data methodology applied to ERAInterim reanalysis data, Water Resour. Res., 50, 7505-7514, doi:10.1002/2014WR015638, 2014.

Zeng, N., Yoon, J.-H., Mariotti, A., and Swenson, S.: Variability of basin-scale terrestrial water storage from a PER water budget method: The Amazon and the Mississippi, J. Climate, 21, 248265, doi:10.1175/2007JCLI1639.1, 2008.

Zhang, L., Dobslaw, H., and Thomas, M.: Globally gridded terrestrial water storage variations from GRACE satellite gravimetry for hydrometeorological applications, Geophys. J. Int., 206, 368-378, doi:10.1093/gji/ggw153, 2016 (data available at: http: //icgem.gfz-potsdam.de/ICGEM/JSB/G3Browser-st.html). 